\title{
Analysis on the Historical Development and Causes of Contemporary New Types of Meticulous Flower- and-bird Painting
}

\author{
Xueting Zhang \\ Inner Mongolia Technical College of Construction \\ Hohhot, China
}

\author{
Yongmei $\mathrm{Wu}$ \\ Shandong University of Arts \\ Jinan, China
}

\begin{abstract}
The development of Chinese meticulous flowerand-bird painting has a history of at least two thousand years. The images of flowers and birds appeared nearly four thousand years ago. Its development process is unmatched, and its lofty achievements cannot be replicated. In the first half of the twentieth century, new ideas began to impact Chinese traditional painting. In this social state, the meticulous flowerand-bird painters began to change from negative coping to active progress, seeking in the embarrassment. They have opened the prelude to the modern process of meticulous flower and bird painting. In the $1950 \mathrm{~s}$ and $1960 \mathrm{~s}$, the meticulous flower-and-bird paintings began to make some innovations in content, form and technique. However, they did not form distinct features. Since the 1980s, with the development of the society and the reform and opening up, culture has entered into an open environment. Under the influence of various artistic trends, especially the new trend in 1985 , the vision of the painters has become wider, and the creative mentality has become free. In the 21 st century, the meticulous flower-andbird paintings have gradually moved from revival to prosperity. The meticulous flower-and-bird paintings with distinctive personality characteristics appeared in large quantities. And the art circle of meticulous flower-and-bird painting showed a prosperous scene. Today, the exhibition number, and the large scale of meticulous flower-and-bird paintings are incomparable in the past, reflecting the good development and creation of meticulous flower-and-bird paintings in recent years. It breaks the characteristics of single style and similarity of the previous art styles, and also breaks the limitations of traditional tool materials, and breaks through the existing difficulty in the aesthetics of Chinese painting. By analyzing its development process, we can better understand the contemporary meticulous flower-and-bird paintings. Also, it points out the direction for future creation.
\end{abstract}

Keywords-contemporary new-style meticulous flower-andbird painting; tradition; history; development

\section{INTRODUCTION}

The meticulous flower-and-bird painting is a branch of the Chinese traditional painting system. Chinese traditional paintings are self-contained in the field of world art. Chinese flower-and-bird paintings reflect the aesthetic relationship between humans and natural creatures, and have strong lyricism. It often reflects the social spirits through the author's thoughts and feelings, and indirectly reflects the social life. Xu Beihong put flower-and-bird paintings into the world art to understand, and proposed that Chinese flowerand-bird paintings had unique qualities and were the special spirit of the Chinese nation. He said: "The highest art in China belongs to painting. The most beautiful works in paintings are flowers and birds, and the second are mountains and rivers, and the last are the figures." Looking at the world, "Chinese flower-and-bird paintings are still a particularly sweet fruit tree in the world art garden. Perhaps China is blessed with strong and pure plum blossoms, elegant fragrant thoroughwort, and beautiful narcissus. These must be strange flowers, and you can't find them in other countries. However, it can truly express the unique character of Chinese artists, and the Chinese national spirit. Therefore, China has many great flower-and-bird painters, such as Song Huizong, Xu Xi, Huang Quan, Huang Jucai, Cui Bai, Zhao Chang, Teng Changyou, etc. The works are beautiful and rival. And there is no rival in the world until now." The vitality of Chinese flower-and-bird paintings is incomparable for European paintings and Japanese paintings. He believes that the Greek art of the source of European civilization is completely manifesting the activities of human beings, not the modality of things. The influence of this tendency is deep and long in the West. There are still fewer flower-and-bird painters in Europe, and there are many character painters."

\section{OVERVIEW}

The meticulous flower-and-bird paintings originated from the ancient lacquer paintings and silk paintings, which prevailed the times between the Tang and Song Dynasties. The era of the courtyard painting in Northern Song Dynasty was a mature period for the meticulous flower-and-bird paintings. And the immortal flower-and-bird paintings such as "Shanhu Jique" and "The Sketch of the Butterfly" and "Sparrow in Cold" appeared. A large number of outstanding painters have appeared. In modern times, the meticulous flower-and-bird paintings absorb the modern art of the West, and in the process of inheritance and innovation, they have developed a large number of excellent works in diversified forms. Some works are based on the tradition, and some works are unique in the art world by combining modern thinking, technical expression and decorative features. 


\section{ThE DEVELOPMENT PROCESS OF METICUlOUS FLOWER-AND-BIRD PAINTING}

The initial stage of Chinese painting is not divided into sections. As the development of paintings continues to enrich the subject, the painting division appears. The Chinese flower-and-bird paintings for more than a thousand years have strong vitality and are still in the state of development.

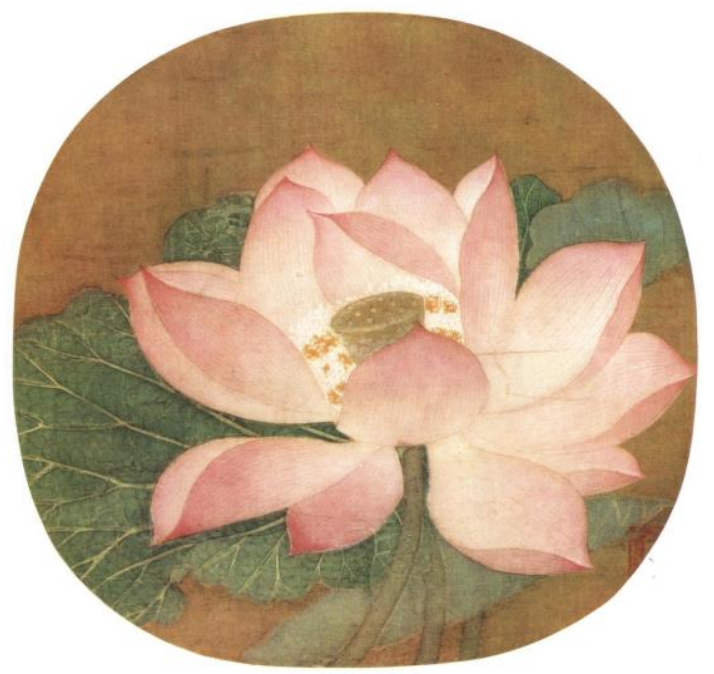

Fig. 1. The image of Song people.

The development history of flower-and-bird paintings has three clear forms. One is the form of flower-and-bird images. The stage of painting birds and flowers hasn't been formed. The second is realistic form. It refers to realistic expression that painting flowers and birds would use line or not. It is divided into two types of performance: coloring and ink. The third is freehand form. The meticulous flower-andbird painting belongs to the realistic form of delineating and subtle expression. The flower-and-bird paintings that appeared as early as 7,000 years ago developed into independent works in the Wei and Jin Dynasties and the Southern and Northern Dynasties. There were painters who specialized in painting flowers and birds. After the independence of flower-and-bird painting, its development process can be divided into four periods. First, it was dominated by the form of meticulous brush and reached the peak period in Tang Dynasty, the Five Dynasties, and the Song Dynasty. (Fig. 1) Second, the technique of painting or drawing changed into ink from the Northern Song Dynasty, and it the realized the transition of ink painting in Yuan Dynasty. Third, it is dominated by ink freehand brushwork and reached its peak in Ming and Qing dynasties. It is also a period of diversified development. Fourth, the flower-andbird paintings absorb the Western art in the modern era. And it is the period of diversified form development with the inheritance and innovation.

\section{A. Development Pattern of Meticulous Flower-and-bird Painting in Early Stage}

Flower-and-bird paintings became an independent painting in the Tang Dynasty, and many outstanding painters emerged. The emergence of "Xu" and "Huang" in Five
Dynasties marked the maturity of flower-and-bird painting. The flower-and-bird paintings in the Song Dynasty were unprecedentedly prosperous. It was the heyday for the development of flower-and-bird paintings. Many masters of flower-and-bird paintings emerged, leaving a lot of famous works for the later generations. With the rise of literati paintings, the meticulous flower-and-bird paintings have gradually become submerged, and they have been in the trough for a long time. During the Opium War, the country was opened by foreign guns and the Western culture forcibly entered. China began the modern history. In the late Qing Dynasty, the Chinese nation, and Chinese culture not only endured in the deep national disasters, but also accepted, absorbed, and merged in the contact and collision with Western culture. Among them, the flower-and-bird paintings adopt the artistic principle of "absorbing the quintessence of Western art" and the development characteristics of western culture without changing the essence of "ink". It has caused the inheritance and transformation of the traditional flowerand-bird painting form. On the one hand, it inherits the traditional freehand style of literati painting, such as $\mathrm{Xu} \mathrm{Gu}$, $\mathrm{Wu}$ Changshuo. At the same time, the small freehand form takes Ren Bonian as the representative of the new appearance. On the other hand, there has been a sense of innovation. For example, Gao Jianfu, Chen Shuren, Gao Qifeng, etc. challenge the old-fashioned painting field with absorbing the Japanese art. At the same time, the new form of Chinese and Western cultures brewed during the Republic of China. There were the Chinese and Western people represented by Xu Beihong, Lin Fengmian and Liu Haisu. Qi Baishi, Huang Binhong, Pan Tianshou, etc. have achieved remarkable achievements in inheriting traditions. At that time, in order to adapt to the needs of the market, the painters didn't lose the true spirits in the trend of commercialization of the works, popularization of the theme, and aesthetic secularization, and held the creative banner of art based on the predecessor's personality. The style is innovative. The flower-and-bird painting at this time is developed in the coexistence of Western culture and Chinese traditional culture. Ren Bonian took over the beauty of the rhythm and styling characteristics, and appropriately blended the freehand technique with the beautiful colors. It reflected the characteristics of Ren Bonian. He is a typical spiritual painter who expresses Chinese culture and art that is rich in tradition and compatible with all foreign cultures and arts. Its aesthetic sense of Chinese and Western art has an important influence on the flower-and-bird painting in 20th century. Its new color attracts the attention. The artistic inspiration quickly absorbed the western painting color of the Shili Ocean, and it was applied to the flower-and-bird paintings, and it was adapted to the era when the East and West cultures began to collide.

\section{B. Development Pattern of Medium-term Meticulous Flower-and-bird Painting}

The traditional "Huang-style" flower-and-bird paintings have been quiet for decades after they were renewed in the late Qing Dynasty. During this period, with the ideological trend of learning from Western paintings, the achievements in the realism of the ancient Chinese courtyards have been 
restored, and people have been rethought about the traditional courtyards. This era has formed four aspects of the development of meticulous flower-and-bird painting. One is to start with the inheritance of ancient law, and the representative is Yu Feian (Fig. 2). The second is to go along the road of combination of Chinese and Western culture, represented by Liu Kuiling. The third is to accept the Song people's courtyard, attracting Japanese style, and adopting the pattern consciousness, represented by Chen Zhifo (Fig. 3). The fourth is to study the achievements of the Song people's courtyard, represented by Li Changbai. The commonality is that "drawing paint or sketch from nature" is subject. And it is oriented to the natural ingestion of objects. It is a feeling. $\mathrm{Yu}$ Feian has worked very hard on the traditional ancient law of meticulous flower-and-bird painting. His works don't lack thoughts and rhythm. It is the representative of the northern style. He is committed to carrying forward the spirit of sketching, re-emphasizing the performance of the scene, and paying attention to the details of the structure. His paintings have great impact on the revival of modern meticulous flower-and-bird paintings. Chen Zhifo's works have strong characteristics of the times, and the principle of "art serving people" dominates his creations. His paintings are based on tradition, absorb the color and shape of Japanese patterns, and develop new styles of meticulous flower-and-bird paintings. The traditional meticulous flower-and-bird paintings are introduced into modern times. His achievements are also the result of the combination of Chinese and Western painting. His key role is to make the new ideas of later meticulous flower-and-bird painting be constantly inspired and expressed in the modernization of thoughts and feelings, the absorption of Japanese paintings and the fusion of Western paintings, and the development of the courtyard tradition. Liu Kuiling is an excellent painter of meticulous animal painting. It combines Western and Chinese paintings. The style is vivid and accurate, and the painting is deeply delicate. The technique uses a threedimensional painting of birds, and the anatomical structure draws the beast. Li Changbai's paintings create a quiet and beautiful style with deep and quiet rhyme.

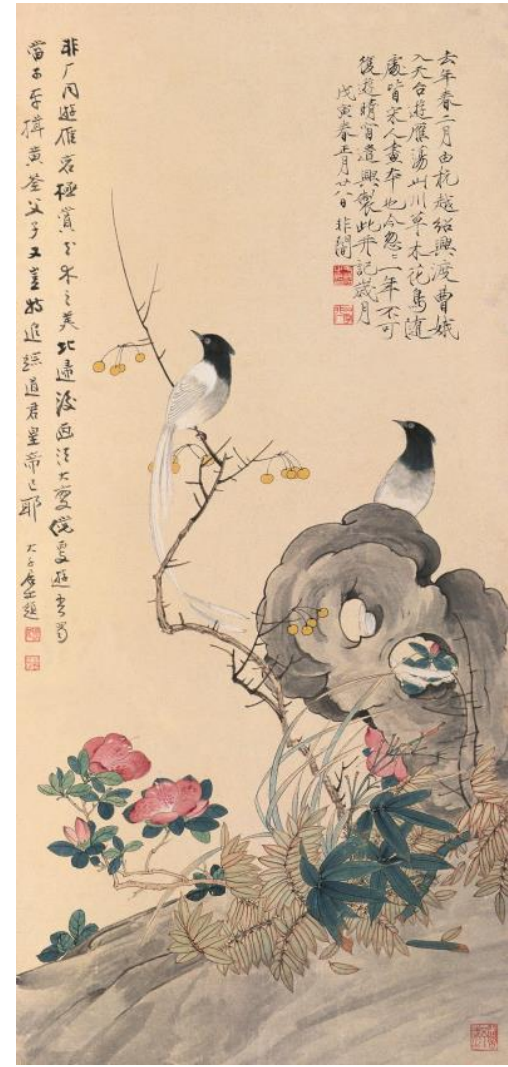

Fig. 2. Yu Feian's works.

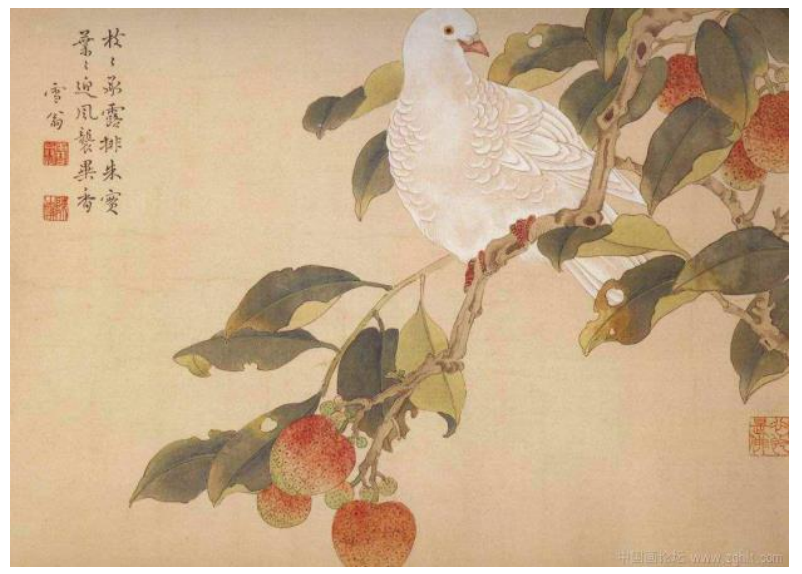

Fig. 3. Chen Zhifo's works

\section{The Development Form of Meticulous Flower-and-bird Painting in the Later Period}

Contemporary meticulous flower-and-bird paintings are clearly a good start after hundreds of years of silence in the mid-Ming Dynasty. After entering the 20th century, the realism of Western paintings flooded into China on a large scale. The principle of literati paintings that did not seek resemblance or adore the characters was violently impacted. Correspondingly, the attention was paid to the styling and realistic meticulous paintings. The realistic performance of Western painting promotes the thinking of traditional 
meticulous painting. Painters born in the late 19th and early 20th centuries have created new dawn for the development of meticulous flower-and-bird painting. With the most rapid development of Chinese painting circles in the past 20 years, contemporary meticulous paintings have not only subverted the aristocratic tendency of traditional literati paintings, but also broke the one-sided and narrow-cut superstition of "putting calligraphy into painting" and "replacing the writing with painting". It has strengthened the painting of Chinese painting. To a large extent, it satisfies the aesthetic orientation of the general public's appreciation of Chinese painting, and conforms to the current consumption demand of the art market.

\section{THE EVOlution OF CONTEMPORARY NEW STYLES OF METICULOUS FLOWER-AND-BIRD PAINTING}

Inheriting tradition and expressing individuality in the current era has become the direction for every artist. They either absorb the fine traditions of the country, the nutrition of foreign art elements, or explore new artistic language. The traditional meticulous flower-and-bird paintings have made breakthroughs and innovations in themes, compositions, colors, materials, techniques and other aspects, forming a new look of contemporary meticulous flower-and-bird paintings. The artists' concept comes from the characteristics of the times. In order to transcend the predecessors and obtain unique personal style, the artists should express something special, such as the "image traits" of contemporary aesthetics and the decorative sense of "popularization", etc. that the predecessors have not experienced. Due to the great convergence of the background of the times, the categorization of personality of many artists has been delineated. And the traditional style of meticulous flower-and-bird paintings has evolved into new type of meticulous flower-and-bird paintings, which is the evolution of art categorization.

Since the 1980s, the tide of ideological emancipation has provided a free-growing atmosphere and a platform for full development of all kinds of artistic concepts. The meticulous flower-and-bird paintings have undergone fission and remodeling, presenting unprecedented contradictions and diversification. Under the dual catalytic turmoil of the information age and the commodity economy, the number of painters, paintings and art exhibitions engaged in meticulous flower-and-bird paintings has increased dramatically, and the scale has grown unprecedentedly. These artists are active in thinking. They either absorb the fine traditions of the country, the nutrition of foreign art elements, or explore new artistic language. The traditional meticulous flower-and-bird paintings have made breakthroughs and innovations in themes, compositions, colors, materials, techniques and other aspects, forming a new look of contemporary meticulous flower-and-bird paintings.

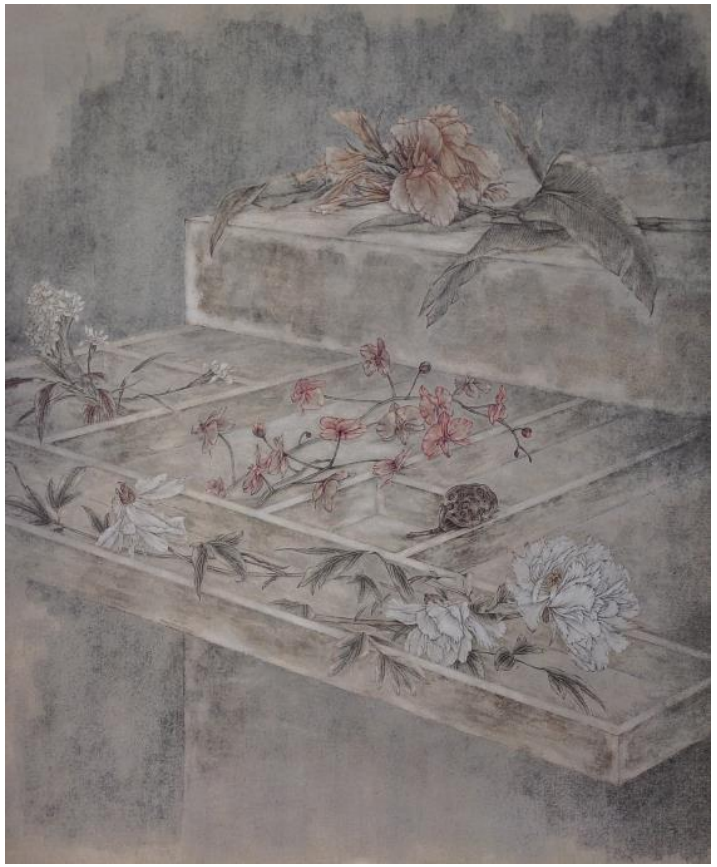

Fig. 4. Lei Miao, "treasure chest".

With the progress and development of society, the expressions and styles of painters who have grown up in specific historical periods and social environments must also be adapted to the background of their growing social culture. Today, painters are relatively free in art selection compared to that in the past, and their creative mentality is relatively easy. With the progress of the times and the development of the economy, people's living standards and education levels have greatly increased. The demand for art consumption has gradually increased. Appreciation and artistic perception are even more inconsistent. Nowadays, the appreciation and creation of meticulous flower-and-bird paintings is not an elite art that serves only a few people, but a daily cultural activity that is generalized to the general public. Advancing with the times and adapting to the trend of popularization has become a prerequisite for the development of contemporary meticulous flower-and-bird paintings. Under the situation of reform, opening up, and cultural pluralism, China's meticulous flower-and-bird paintings have created an artistic peak. Compared with the traditional meticulous flower-andbird paintings that have a glorious history, there are insurmountable traditional art and the impact of foreign art.

\section{CONCLUSION}

Seeking change is the law of all artistic development. Due to the limitations of traditional flower-and-bird paintings, most of the meticulous flower-and-bird paintings cannot directly reflect social life. And each artist would work for inheriting tradition and expressing individuality. However, inheriting the tradition is not simply copying the ancient meanings, but to innovate and develop on the basis of tradition. In the process of expressing individuality and innovation, it does not abandon tradition or stay away from tradition. In order to have the changes and development, it should be explored and studied from multiple perspectives, 
all directions and deep levels. Contemporary new-style meticulous flower-and-bird paintings should critically inherit the tradition, and the essence and excellent parts should be reconstructed in combination with modern aesthetics. It is not advisable to abandon tradition or deviate from tradition. Through understanding the essence of the phenomenon, the basic source of contemporary new meticulous flower-andbird paintings should also be the Chinese traditional meticulous flower-and-bird paintings. In the future, creation should be based on tradition. And we should learn from others. Based on the contemporary, the artists should inherit the tradition, carry forward the national spirit, absorb the foreign art and sister art, and broaden the creation. Our outstanding national art will last forever.

\section{REFERENCES}

[1] Kong Liuqing. The History of Chinese Painting Art, Flower and Bird Volume $[\mathrm{M}]$. Nanchang: Jiangxi Fine Arts Publishing House, 2008: 10-603 孔六庆.中国画艺术专史. 花鸟卷 [M].南昌: 江西美术 出版社, 2008: 10-603

[2] Li Zhujin, Wan Qingli. History of Modern Chinese Painting [M]. Shanghai: Wenhui Publishing House, 2004: 120-250 李铸晋, 万青 力.中国现代绘画史 [M] . 上海: 文汇出版社, 2004：120-250

[3] Zhou Jiyin. Chinese Painting Theory [M]. Nanjing: Jiangsu Fine Arts Publishing House, 2007: 1-878 周积寅.中国历代画论 [M] . 南 京: 江苏美术出版社, 2007: 1-878

[4] Cao Yulin. Physical Transformation of Contemporary Chinese painting $[\mathrm{M}]$. Shanghai: Shanghai Painting and Calligraphy Publishing House, 2006: 61-205 曹玉林. 当代中国画体格转型 [M].上海: 上海书画出版社, 2006: 61-205

[5] Luo Yiping. Language and Schema: Images of Flowers and Birds in the History of Chinese Art $[\mathrm{M}]$. Guangzhou: Lingnan Fine Arts Publishing House, 2006: 1-381 罗一平.语言与图式: 中国美术史 中的花鸟图像 [M].广州: 岭南美术出版社, 2006: 1-381

[6] Song Xiaoxia. Research on the Tradition and Modern Development of Meticulous Painting [D]. Beijing: Central Academy of Fine Arts, 2008. 宋晓霞. 工笔画的传统与现代发展研究 [D ] . 北京: 中央 美术学院, 2008 